\title{
Aspirin: Antiinflammatory Drug of Choice in 2011?
}
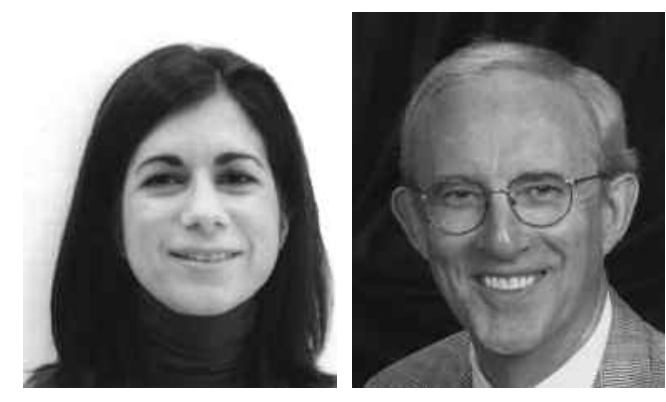

Now that 40 years have passed since the introduction of ibuprofen, and 6 years since the recall of rofecoxib, we must examine the question: Are non-aspirin nonsteroidal antiinflammatory drugs (NSAID) more effective or less toxic than aspirin (acetylsalicylic acid, ASA)? We suggest that ASA, with its indisputable antiinflammatory properties and better side effect profile [with respect to cardiovascular (CV), kidney, and central nervous system (CNS) toxicities] should be reconsidered as antiinflammatory of choice in certain patient populations.

The landscape of NSAID use has changed over the years, as reflected by changing prescription patterns. In this issue of The Journal, a study by Rahme and colleagues ${ }^{1}$ examines the differences in prescribing patterns pre- and post-rofecoxib removal among patients with variable degrees of gastrointestinal (GI), CV, and renal risk factors. To understand the current outlook on NSAID use and the present changing prescription practices, however, we must first take a look at the history of NSAID use.

Use of ASA-like compounds predates modern times. Ancient Egyptians are credited for using willow tree bark, which they applied to stiff and painful joints. Hippocrates recommended willow tree preparations from the inner bark for alleviating symptoms of pain, fever, and inflammation. It was not until the 18th century, however, that the compound responsible for the antiinflammatory effects of willow, salicylic acid, was discovered ${ }^{2,3}$. Salicylic acid was found to have antiinflammatory properties, although it caused GI side effects. In 1899, the German chemist for Bayer Company, Felix Hoffman, perfected the process of synthesizing salicylic acid, making it less gastrotoxic, which led to the patent of the first truly synthetic drug: Aspirin ${ }^{3}$.

ASA use quickly became widespread, and it was not until 1938 that endoscopic evidence of ASA-induced gastric toxicity in several patients was demonstrated ${ }^{4}$. These gastric problems became increasingly recognized over the following years. In 1965, a new drug with analgesic and antiinflammatory properties appeared on the market: indome- thacin. Indomethacin was proven to be an effective NSAID, although it carried the risk of adverse GI effects, as well as risk of developing renal insufficiency and hepatotoxicity ${ }^{5}$. In 1974, the US Food and Drug Administration (FDA) approved another new NSAID, ibuprofen. Although initial trials in patients with rheumatoid arthritis showed no benefit over placebo, ibuprofen, through successful promotion, soon became one of the most popular non-ASA NSAID ${ }^{3}$.

With the emergence and promotion of a number of non-ASA NSAID, the use of ASA for its antiinflammatory properties declined because of concerns regarding its GI adverse effects. It was soon discovered, however, that non-ASA NSAID not only have GI adverse effects, but also carry other adverse effects matching and even surpassing those of ASA, particularly in certain patient populations.

Non-ASA NSAID have been found to increase blood pressure in hypertensive and even in normotensive people. This hypertensive effect is dose-dependent and involves, at least in part, the inhibition of cyclooxygenase-2 (COX-2) in the kidneys, which causes reduced sodium excretion and increased intravascular volume ${ }^{5}$. Although ASA does have some COX-2-inhibiting properties, it has not been shown to have the same hypertensive effects. In 1993 and 1994, 2 large metaanalyses were performed (Pope, et al and Johnson, et al, respectively) to determine hypertensive effects of NSAID ${ }^{6,7}$. While the first metaanalysis found the effects of NSAID on blood pressure solely in hypertensive subjects, there was consensus between both studies that ASA, even at antiinflammatory doses, has the least hypertensive effect of all NSAID reviewed.

In 2002, a prospective study of women without hypertension who participated in the Nurses Health Study II examined the association between analgesics and risk of incident hypertension ${ }^{8}$. After adjustment for age and other potential risk factors, only non-ASA NSAID and acetaminophen were significantly associated with risk of hypertension [relative risk (RR) of hypertension for women taking each medication at least 22 days of the month was 2.00

\section{See Utilization of NSAID after rofecoxib, page 195}

Personal non-commercial use only. The Journal of Rheumatology Copyright $@$ $~ 2011$. All rights reserved. 
for acetaminophen, 1.43 for NSAID, and 0.89 for ASA]. Similar findings were described in a study looking at incident hypertension in a cohort of healthy men. Forman, et al studied male health professionals without baseline hypertension. The RR of incident hypertension for subjects taking analgesics 6-7 days/week was as follows: 1.34 for acetaminophen $(\mathrm{p}=0.01), 1.38$ for NSAID $(\mathrm{p}=0.002)$, and 1.26 for ASA $(p \leq 0.001)^{9}$. Although dosages of ASA were not provided, the trend certainly is consistent with earlier studies.

Because the proposed mechanism for hypertensive effects of NSAID is related to COX-2 inhibition in the kidneys, selective COX-2 inhibitors were also shown to increase blood pressure. To study the effects on blood pressure of selective COX-2 inhibitors compared to nonselective, non-ASA NSAID, a metaanalysis performed by Aw, et $a l^{10}$ revealed increased systolic and diastolic blood pressure associated with selective COX-2 inhibitors, compared to placebo $(2.81 \mathrm{~mm} \mathrm{Hg} / 1.06 \mathrm{~mm} \mathrm{Hg}$ ) and compared to nonselective NSAID $(2.81 / 1.34 \mathrm{~mm} \mathrm{Hg})^{10}$.

Perhaps related to their hypertensive effects, non-ASA NSAID, including selective COX-2 inhibitors, have been associated with acute and chronic renal failure ${ }^{11,12,13,14}$. In 1989, Sandler, et al looked at the association between analgesic use and chronic renal disease ${ }^{12}$. There was an increased risk of kidney disease with longterm, daily acetaminophen use, but no increased risk in daily users of ASA (doses of ASA were not provided). Perneger, et al $^{13}$ expanded on the previous study by including NSAID use to determine an association with analgesics and risk of starting hemodialysis. Acetaminophen and non-ASA NSAID use were both found to be associated with increased risk of endstage renal disease (ESRD) in a dose-dependent manner. Again, ASA was found not to have an increased odds ratio of ESRD ${ }^{13}$.

Another potential benefit of ASA over other NSAID is its lack of association with aseptic meningitis. NSAID-associated aseptic meningitis was first described in 1978 by Widener and Littman ${ }^{15}$. It is seen most commonly in young women with lupus with prior history of NSAID use. Within hours of reintroduction of NSAID comes the onset of fevers, headache, and stiff neck. Ibuprofen is the NSAID most commonly linked to this condition, although cases involving sulindac, naproxen, tolmetin, and diclofenac have been reported $^{16,17}$. To date, there have been no reported cases of aseptic meningitis with ASA use.

Other advantages of ASA therapy include ease of dosing and the monitoring of drug levels in the blood. The dose of ASA associated with specific effects has been carefully studied. Antiplatelet effects can be achieved at doses of 81-325 mg daily. Analgesic/antipyretic doses are 325-650 mg every 4-6 hours. Antiinflammatory effects are seen at doses of 3-5.4 g daily, or target blood salicylate levels of $150-300 \mu \mathrm{g} / \mathrm{ml}^{18}$. The ability to monitor ASA levels by sim- ple blood tests allows easy administration and dosing, as compared to other NSAID, for which dosing is not individualized because the upper limits cannot be determined by blood levels.

Despite the numerous benefits of ASA for antiinflammatory purposes, the risk it carries for GI complications is an important and valid concern, and likely the largest factor limiting its use. Although ASA has generally been used as reference, non-ASA NSAID have also been implicated in upper GI bleeding ${ }^{3,19}$. After many attempts at ranking NSAID in terms of GI toxicity, results were mixed, likely reflecting the fact that all NSAID were not compared at their equivalent doses ${ }^{3,19}$.

The mechanism of action of NSAID-induced GI toxicity has largely been attributed to their effect on COX-1. Although local gastroduodenal injury may occur, the more central role in the pathogenesis of NSAID-associated gastroduodenal ulcers is related to the inhibition of prostaglandin synthesis $3,20,21$. The inhibition of GI prostaglandin $\mathrm{E}_{2}$ synthesis leads to increased gastric acid synthesis, decreased production of the protective superficial mucosal barrier, decreased bicarbonate synthesis, and decreased control of mucosal blood flow in the superficial gastric cell layers. As both ASA and non-ASA NSAID inhibit COX-1, it is reasonable to expect the same potential for GI toxicity with the use of all NSAID.

Prescribing non-ASA NSAID to avoid adverse gastric effects of ASA is no longer a choice without consequence. In addition to their potential renal, hypertensive, GI, and CNS toxicities, recently there has been renewed focus on potential $\mathrm{CV}$ events. In general, prostaglandins in the endothelial cell are dependent on COX-2 induction, particularly in atherosclerosis ${ }^{21,22}$. NSAID that have anti-COX-2 effects, therefore, may increase potential for thrombogenesis and decreasing prostaglandin-derived vasodilation. In the case of COX-2-selective NSAID, the combination of irreversible binding of COX-2 and lack of COX-1 inhibition has been shown to favor thrombogenesis and vasoconstriction, thus potentially leading to increased risk for $\mathrm{CV}$ events. This raised risk led to removal of the COX-2-selective NSAID rofecoxib from the market in 2004. Subsequently, the Food and Drug Administration concluded that all NSAID (excluding ASA) may carry an increased risk of serious adverse CV effects. ASA's prolonged antiplatelet effect may nullify this risk carried by other NSAID.

The removal of rofecoxib certainly made an impact on the NSAID market, with more attention given to patient baseline risk factors prior to selecting an NSAID. As such, guidelines for prescribing NSAID were developed, as referenced by Rahme, et al ${ }^{1}$. Tables plotting CV risk against GI risk identify patients who would benefit from proton-pump inhibitor prophylaxis, the addition of low-dose aspirin, or the complete avoidance of NSAID in general. This trend was demonstrated clearly in the "Utilization" $\operatorname{article}^{1}$ by

Personal non-commercial use only. The Journal of Rheumatology Copyright $(\subset) 2011$. All rights reserved. 
demonstrating a difference in the characteristics of patients in Canada receiving various NSAID post-rofecoxib withdrawal, compared to the pre-withdrawal period. Overall, the authors found a decrease of $18.5 \%$ in the utilization of celecoxib in the post-withdrawal period, while the utilization of other non-ASA NSAID increased by $106 \%$. Additionally, high-risk CV patients were overall less likely to be prescribed a non-ASA NSAID (selective or nonselective) in the post-refocoxib period. Renal and congestive heart failure risk levels did not seem to differ between NSAID groups or time period, perhaps because of lack of sufficient evidence implicating one group of non-ASA NSAID over another, in terms of these particular risk factors ${ }^{1}$.

The concern over potential adverse effects of NSAID has already led to a change in prescribing habits. With more data, patterns may continue to change, even perhaps with a move back to ASA. At this time, there clearly is no risk-free antiinflammatory medication. An ideal formulation would share several qualities with ASA: its ease of monitoring levels, little effect on blood pressure and renal function, combined with its cardioprotective - not cardiotoxic properties, but would not carry risk of GI bleeding. Until this new medication appears, however, it is worth considering a return to ASA, in sufficient doses and possibly with a concomitant proton-pump inhibitor, as the antiinflammatory of choice, particularly in patients with hypertension, atherosclerotic disease, chronic kidney disease, and lupus.

ALEXANDRA M. TILIAKOS, $\mathrm{MD}$, Fellow, Division of Rheumatology;

DOYT L. CONN, MD,

Professor of Medicine,

Director, Division of Rheumatology,

Emory University School of Medicine, Atlanta, Georgia, USA

Address correspondence to Dr. A. Tiliakos, Division of Rheumatology, Emory University, 49 Jesse Hill Jr Drive SE, Atlanta, GA 30303.

E-mail: atilia2@emory.edu

\section{REFERENCES}

1. Rahme E, Roussy JP, Lafrance JP, Nedjar H, Morin S. Utilization of nonsteroidal antiinflammatory drugs: Is there a change in the patient risk profile after withdrawal of rofecoxib? J Rheumatol 2011;38:195-202.

2. Jack DB. One hundred years of aspirin. Lancet 1997;350:437-9.

3. Vonkeman HE, van de Laar MA. Nonsteroidal antiinflammatory drugs: adverse effects and their prevention. Semin Arhtritis Rheum 2010;39:294-312.

4. Douthwaite AH, Linott SAM. Gastroscopic observation of the effect of aspirin and certain other substances on the stomach. Lancet 1938;2:1222-5.
5. Kurth T, Hennekens CH, Sturmer T, Sesso HD, Glynn RJ, Buring JE, et al. Analgesic use and risk of subsequent hypertension in apparently healthy men. Arch Intern Med 2005;165:1903-9.

6. Pope J, Anderson J, Felson D. Metaanalysis of effects of nonsteroidal antiinflammatory drugs on blood pressure. Arch Intern Med 1993;153:477-84.

7. Johnson A, Nguyen T, Day R. Do nonsteroidal antiinflammatory drugs affect blood pressure? Ann Intern Med 1994;121:289-300

8. Curhan GC, Willett WC, Rosner B, Stampfer MJ. Frequency of analgesic use and risk of hypertension in younger women. Arch Intern Med 2002;162:2204-8.

9. Forman J, Rimm E, Curhan G. Frequency of analgesic use and risk of hypertension among men. Arch Intern Med 2007;167:394.

10. Aw T, Haas S, Liew D, Krum H. Meta-analysis of cyclooxygenase-2 inhibitors and their effects on blood pressure. Arch Intern Med 2005; 165:490-6.

11. Schneider V, Levesque L, Zhang B, Hutchinson T, Brophy JM. Association of selective and conventional nonsteroidal antiinflammatory drugs with acute renal failure: a population based nested case-control analysis. Am J Epidemiol 2006;164:881-9.

12. Sandler DP, Smith JC, Weinberg CR, Buckalew VM Jr, Dennis VW, Blythe WB, et al. Analgesic use and chronic renal disease. New Engl J Med 1989;320:1238-43.

13. Perneger TV, Whelton PK, Klag MJ. Risk of kidney failure associated with use of acetaminophen, aspirin, and nonsteroidal antiinflammatory drugs. New Engl J Med 1994;331:1675-9.

14. Swan SK, Rudy DW, Lasseter KC, Ryan CF, Buechel KL, Lambrecht LJ, et al. Effect of cyclooxygenase-2 inhibition on renal function in elderly persons receiving a low salt diet. Ann Intern Med 2000;133:1-9.

15. Widener HL, Littman BH. Ibuprofen-induced meningitis in systemic lupus erythematosus. JAMA 1978;239:1062-4.

16. Hoppmann RA, Peden JG, Ober SK. Central nervous system effects of nonsteroidal antiinflammatory drugs. Arch Intern Med 1991;151:1309-13

17. Ostensen M, Villiger PM. Nonsteroidal antiinflammatory drugs in systemic lupus erythematosus. Lupus 2001;10:135-9.

18. Furst D, Munster T. Nonsteroidal antiinflammatory drugs, diseasemodifying antirheumatic drugs, nonopioid analgesics, and drugs used in gout. In: Katzung B. Basic and clinical pharmacology. 8th ed. New York: Lange Medical Books/McGraw-Hill; 2001:596-620.

19. Laporte JR, Carne X, Vidal X, Moreno V, Juan J. Upper gastrointestinal bleeding in relation to previous use of analgesics and nonsteroidal antiinflammatory drugs. Catalan Countries Study on Upper Gastrointestinal Bleeding. Lancet 1991;337:85-9.

20. Simon LS, Goodman T. Nonsteroidal antiinflammatory drug-induced gastrointestinal toxicity. Bull Rheum Dis 1995;44:1-5.

21. Miller SB. Prostaglandins in health and disease: an overview. Semin Arthritis Rheum 2006;36:37-49.

22. Solomon DH, Schneeweiss S, Glynn RJ, Kiyota Y, Levin R, Mogun $\mathrm{H}$, et al. Relationship between selective cyclooxygenase-2 inhibitors and acute myocardial infarction in older adults. Circulation 2004;109:2068-73.

J Rheumatol 2011;38:185-7; doi:10.3899/jrheum.100801 